Sādhanā, Vol. 24. Part 6. December 1999. pp. 551-555. ¿. Printed in India

\title{
Development of free-standing submicron Formvar films with multiple thickness steps for XUV-soft X-ray applications
}

\author{
A CHOWDHURY, P A NAIK and P D GUPTA \\ Plasma Radiation Laboratory, Centre for Advanced Technology, Indore \\ 452013, India \\ e-mail: avijit@cat.ernet.in
}

MS received 26 August 1998; revised 5 January 1999

\begin{abstract}
Preparation of free-standing submicron Formvar films with multiple thickness steps is reported. This is done by using a dipping and pulling technique in which film thickness is controlled by varying the pulling speed. Dependence of film thickness on the pulling speed is presented. Planar unsupported films of a single thickness or with multiple thickness steps in the range of $0.25 \mu \mathrm{m}$ to $\sim 5 \mu \mathrm{m}$ and of area up to $\approx 800 \mathrm{~mm}^{2}$ are made in this manner. Such films should be useful in XUV-soft X-ray spectral measurements and as targets for plasma ablation studies.
\end{abstract}

Keywords. Submicron thick films; step thickness X-ray filters; XUV-soft $\mathrm{X}$-ray spectroscopy.

\section{Introduction}

Development of free-standing submicron thick organic films is an area of much interest due to their wide range of applications. This is particularly important due to the necessity of inhouse fabrication of such films in the laboratory owing to their fragile nature. These films, with or without additional coatings on them, are used for XUV-soft X-ray spectroscopy (Kornblum \& Kauffman 1986; Popil et al 1987; Kent et al 1990; Stephan et al 1993; Li Yuelin et al 1995; Sailaja et al 1998) such as band-pass filters for X-ray diodes, cut-off filters for X-ray spectrographs etc. In the latter case, free-standing films are required to avoid any complication in the recorded spectrum arising due to the support structure. Next, these films are used as substrates for coating CsI or gold to make transmission photocathodes for X-ray streak cameras, as vacuum windows for mounting live biological samples for X-ray microscopic imaging (Chakera et al 1998), as plasma targets in inertial confinement fusion research (Hogan 1995), and as thin film targets for X-ray laser work (Mathews et al 1985). In most of these applications, films of a single uniform thickness are used. However, there are several applications in which free-standing submicron thick organic films with two or more thickness steps are required. For instance, $X$-ray spectra transmitted through such multi-step filters would not only increase the intensity range of the emission 
spectrum that can be recorded in a single shot, but also provide a convenient means of in situ intensity calibration of the detector used. Further, films with one or more thickness steps can be useful in shock propagation studies (Coe et al 1988) where arrival of the shock, after travelling through different thicknesses in the film, is detected for shock-speed measurements.

Submicron thick organic films have been prepared by several methods, viz. spreading a solution of the organic material on water (Kent et al 1990), chemical vapour deposition (Stephan et al 1993), stretching (Barrus \& Blake 1977; Stephan et al 1994), spincoating (Stephan et al 1994), and dipping and draining (Popil et al 1986). All these, however, have been used to make films of a single thickness only. Development of single films with multiple thickness steps has not been reported. In this paper, we present a simple and low-cost method of making free-standing single films of Formvar $\left(\mathrm{C}_{5} \mathrm{H}_{7} \mathrm{O}_{2}\right)$ with multiple thickness steps using a dipping and pulling technique in which the film thickness is controlled by varying the pulling speed. Formvar was chosen as the film material because of its higher tensile strength compared to other organic films e.g. Parlodion $\left(\mathrm{C}_{12} \mathrm{H}_{16}\left(\mathrm{NO}_{3}\right)_{4}\right)$, Zapon $\left(\mathrm{C}_{5} \mathrm{H}_{7} \mathrm{O}_{11} \mathrm{~N}_{3}\right)$, Saran $\left(\mathrm{C}_{2} \mathrm{H}_{2} \mathrm{Cl}_{2}\right)$ etc. which are also used as $\mathrm{X}$-ray filters. Moreover, Formvar film of a given thickness has a lower energy cutoff and a simpler transmission profile because of a relatively larger fraction of carbon constituent.

\section{Method of preparation}

Thin films are deposited by a dipping and pulling technique. It basically involves immersing a glass slide in a solution of the organic material and then pulling it vertically upwards out of the solution. Film thickness depends on the solution concentration and the pulling rate. Films of smaller thickness are deposited on the glass slide when the latter is pulled out slowly and vice versa. A constant pulling speed is required to produce films of uniform thickness. On the other hand, pulling rate can be varied to deposit films of a desired thickness profile along the direction of pulling. The dipping and pulling technique is advantageous compared to the dipping and draining version (Popil et al 1986) in which the glass slide is kept stationary and the solution is drained out using a stop-cock arrangement. In the latter case, thickness uniformity may be affected since the draining rate changes due to reduction in the level of solution in the container. Further, this can be used for depositing films of a single thickness only.

Films are deposited on glass slides of size $25 \mathrm{~mm} \times 75 \mathrm{~mm}$ or $50 \mathrm{~mm} \times 50 \mathrm{~mm}$. Formvar solutions of different concentrations are prepared by dissolving calculated amounts of Formvar in acetic acid. For instance, a $5.5 \%$ solution is made by dissolving $6.1 \mathrm{gm}$ of Formvar in $100 \mathrm{ml}$ of acetic acid. The slides are pulled vertically upwards using a motorized translational stage at different speeds in the range of $5 \mu \mathrm{m} / \mathrm{s}$ to $200 \mu \mathrm{m} / \mathrm{s}$. A thin film gets cast on both the sides of the glass slide as it is pulled out. An adhesive tape frame of rectangular shape is pasted on the dried film surface along its boundary. The slides are then dipped in warm water $\left(\sim 35^{\circ} \mathrm{C}\right)$ for a minute and then taken out. The film is peeled off along with the boundary frame. For pulling speeds of $30 \mu \mathrm{m} / \mathrm{s}$ and higher, the films reflect in a single colour, which is the primary indication of the uniformity of the film thickness. However, for pulling speeds smaller than $30 \mu \mathrm{m} / \mathrm{s}$, the films are very thin and cannot be peeled off without breaking. Moreover, they show multiple colour interference fringes in reflected light, indicating gross non-uniformity in thickness. 


\section{Results and discussion}

Film thickness measurements were carried out using a modified Jamin interferometer (Shukla et al 1994) and a DEKTAK surface profilometer. In the former case, film thickness was determined by measuring the fringe shift introduced by the film using a thin-wedge technique. The procedure for these measurements is described in detail by Shukla et al (1994). Profilometer thickness measurements were done prior to peeling off of the film from the glass slide. Since a profilometer measures thickness difference across a sharp step, the film was cut from the side by using a sharp blade and peeled off using an adhesive tape. For checking uniformity of thickness of the film, the same procedure was applied to different parts of the film and measurements were made at different places. We found that the film thickness (at a constant pulling rate) was uniform within $\pm 6 \%$. This is quite adequate for X-ray filter applications as the transmission of a Formvar film of $0.5 \mu \mathrm{m}$ thickness and the level of non-uniformity will change only by a maximum of $\sim 6 \%$ and $\sim 0.3 \%$ for $\mathrm{X}$-ray photon energies of $0.5 \mathrm{keV}$ and $2 \mathrm{keV}$ respectively.

Dependence of film thickness on pulling rate is shown in figure 1. Films of thickness from $0.25 \mu \mathrm{m}$ to $0.9 \mu \mathrm{m}$ were obtained from $5.5 \%$ solution for pulling speed range of $30 \mu \mathrm{m} / \mathrm{s}$ to $200 \mu \mathrm{m} / \mathrm{s}$. Films of larger thicknesses were obtained using solutions of higher concentration. Variation of film thickness with pulling speed for a concentration of $9 \%$ is also shown in figure 1. It may be noted from the figure that film thickness increases linearly with pulling speed. For smaller pulling speeds, the meniscus remains in contact with the glass slide for a longer duration. This results in a thinner film as more and more molecules are pulled back from the glass slide into the solution due to surface tension characteristics. Free-standing films of single thickness in the range of $0.25 \mu \mathrm{m}$ to $\sim 5 \mu \mathrm{m}$ and of area up to $\sim 800 \mathrm{~mm}^{2}$ were produced using appropriate pulling speeds and solution concentrations.

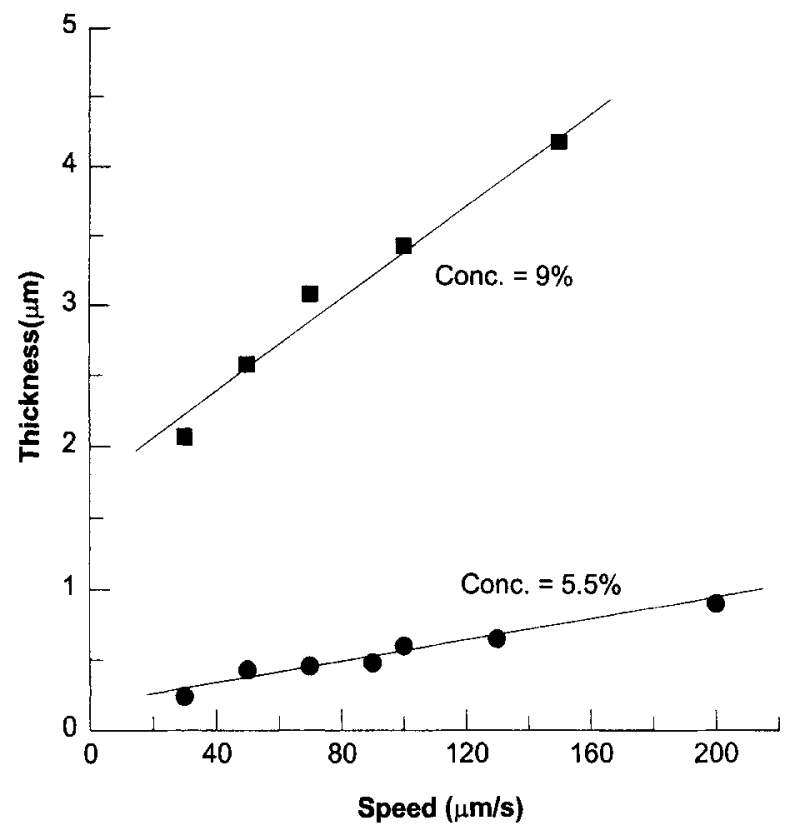

Figure 1. Dependence of film thickness on pulling speed. 


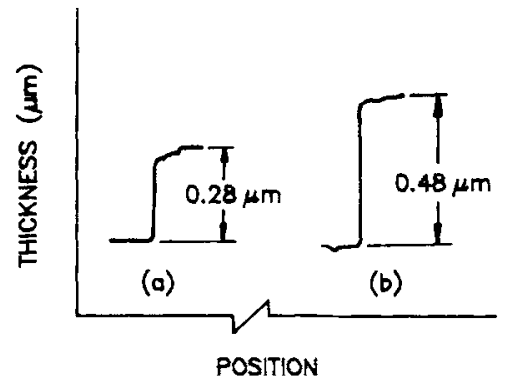

Figure 2. Profilometer scans in a step thickness Formvar film.

The observed dependence of film thickness on pulling speed (figure 1) was used to deposit films with multiple thickness steps by changing the pulling speed through the translational stage controller. The length of the film portion of a particular thickness was determined by the duration of translational stage movement and the pulling speed required for that thickness. Formvar films with two/three regions of different thicknesses were deposited in this manner. Figure 2 shows profilometer scans on either side of a thickness step, midway in a Formvar film of size $50 \mathrm{~mm} \times 16 \mathrm{~mm}$. Film thicknesses of $0.25 \mu \mathrm{m}$ and $0.48 \mu \mathrm{m}$ were measured corresponding to pulling speeds of $30 \mu \mathrm{m} / \mathrm{s}$ and $90 \mu \mathrm{m} / \mathrm{s} \mathrm{respec-}$ tively. The width of the thickness step was $\leq 1 \mathrm{~mm}$, and this was due to manual change of speed-setting on the control. However, desired variation in the speed can be programmed to make even sharper steps that may be required for a particular application. Moreover, films with graded thickness can be made by continuously changing the pulling speed.

\section{Conclusion}

In conclusion, free-standing Formvar films of a single thickness or with multiple thickness steps in the range of $0.25 \mu \mathrm{m}$ to $5 \mu \mathrm{m}$ are developed. Such films should be useful in XUVsoft X-ray spectroscopy, as targets in X-ray laser research and plasma ablation studies, and as substrates for photocathodes for X-ray streak cameras.

The authors thankfully acknowledge help provided by $\mathrm{T}$ Sharma and $\mathrm{M}$ Gokhle in profilometer measurements (Tata Institute of Fundamental Research, Mumbai) and by R P Shukla in interferometry measurements (Bhabha Atomic Research Centre, Mumbai).

\section{References}

Barrus D M, Blake R L 1977 Technique for producing ultrathin polypropylene films. Rev. Sci. Instrum. 48: 116-117

Chakera J A, Kumbhare S R, Gupta P D 1998a Characterization of X-ray contact microscopic imaging in keV spectral region using laser produced plasmas. J. X-ray Sci. Technol. 8: 1-9

Chakera J A, Gupta P D, Geondgian Yu, Sorokin V V, Korol V Yu, Avtonomov V 1998b X-ray contact microscopic imaging in keV spectral region using laser produced plasmas. Curr. Sci. 74: $54-58$

Coe S E, Willi O, Afshar-Rad T, Rose S J 1988 Study of shock coalescence in laser-irradiated targets. Appl. Phys. Lett. 53: 2383-2385 
Hogan W G 1995 Energy from inertial fusion. STI/PUB/944, International Atomic Energy Agency, Vienna

Kent B J, Reading D H, Swinyard B M, Graper E B, Spurrett P H 1990 EUV band pass filters for the ROSAT wide field camera. Proc. Soc. Photo-Opt. Instrum. Eng. 1344: 255-266

Kornblum H N, Kauffman R L 1986 Measurement of 0.1-3 keV X-rays from laser plasmas. Rev. Sci. Instrum. 57: 2179-2181

Li Yuelin, Tsakiris G D, Sigel S 1995 Self calibration of a thinned, backside illuminated charge coupled device in the soft X-ray region. Rev. Sci. Instrum. 66: 80-86

Mathews D L et al 1985 Demonstration of a soft X-ray amplifier. Phys. Rev. Lett. 54: 110-113

Popil R, Haromy A, Fedosejevs R, Offenberger A A 1986 Preparation of planar multilayer targets for laser ablation studies. Rev. Sci. Instrum. 57: 2625-2627

Popil R, Gupta P D, Fedosejevs R, Offenberger A A 1987 Measurement of KrF laser plasma X-ray radiation from targets with various atomic numbers. Phys. Rev. A35: 3874-3882

Sailaja S, Arora V, Kumbhare S R, Naik P A, Gupta P D, Fedin D A, Rupasov A A, Shikanov A S 1998 A simple XUV transmission grating spectrograph with sub- $\AA$ resolution for laser plasma interaction studies. Meas. Sci. Technol. 9: 1462-1468

Shukla R P, Chowdhury A, Gupta P D 1994 Interferometric determination of thickness of freestanding submicron Formvar films. Opt. Eng. 36: 1881-1884

Stephan K H, Brauninger H, Reppin C, Maier H J, Frischke D, Krumrey M, Muller P 1993 Optical filters for X-ray astronomy CCDs. Nucl. Instrum. Methods Phys. Res. A334: 229-233

Stephan K H, Reppin C, Maier H J, Frischke D, Fuchs D, Muller P, Moller S, Gurtler P 1994 Transmittance performance of polypropylene, poly-para-xylene and polycarbonate films in the photon energy range from $1 \mathrm{eV}$ to $10 \mathrm{keV}$. Proc. Soc. Photo-Opt. Instrum. Eng. 2297: 134-142 